\title{
WHAT FORCES DRIVE THE DYNAMIC INTERACTION BETWEEN REGIONAL HOUSING PRICES?
}

\author{
Yun-Ling WU a , Chien-Lin LU ${ }^{b}$, Ming-Chi CHEN ${ }^{\text {b,* }}$, Fang-Ni CHU c \\ a Department of Real Estate Management, National Pingtung University, Pingtung 900, Taiwan \\ ${ }^{b}$ Department of Finance, National Chengchi University, Taipei, Taiwan \\ ${ }^{c}$ CNCCU - SINYI Research Center for Real Estate, Taipei, Taiwan
}

Received 17 November 2015; accepted 9 May 2016

\begin{abstract}
This paper examines the dynamic interaction between regional housing prices in the United States. We use the copula method to explore the dependent distribution of housing prices in ten metropolitan statistical areas (MSAs) in three regions. The results generally show that changes in time-varying correlation result from different trends in regional housing prices. We regress housing price dynamic correlation on regional economic variables, finding that the economic co-movement mechanism determines the housing price correlation in the Western and Great Lakes regions, while the migration mechanism drives the housing price correlation in the Eastern region. We also find that economic co-movement is the main force driving the housing price correlation between regions.
\end{abstract}

KEYWORDS: Copula model; Dynamic correlation; Regional housing prices

\section{INTRODUCTION}

The interaction and co-movement between regional housing prices have long been important issues for real estate studies. In particular, since the subprime crisis in 2008, the collapse of the housing market has revealed that housing prices in different regions move simultaneously, although they are characterized by different economic conditions. Indeed, there is an invisible linkage between housing markets, which will be stronger in certain specific economic conditions. However, few studies have explored this invisible linkage or its determinants, in particular, because there are limits to investigating the time-varying interaction in regional housing prices.

Many studies have examined housing price connections from the perspective of the ripple effect (e.g., Meen 1999; Chien 2010; Gupta, Miller 2012). Another set of studies has discussed the co-movement of housing prices. Miao et al. (2011) provide strong evidence to support the interconnectedness of housing markets, indicating that the linkages might be attributed to both information diffusion and population migration. Zhu

\footnotetext{
* Corresponding author. E-mail: mcmchen@nccu.edu.tw
}

et al. (2013) highlight the importance of economic interdependence in this interactive process. Kallberg et al. (2014) show that co-movements among regional markets increased considerably in the late 1990s and that this increase was more attributable to fundamental factors rather than to contagion. Generally, prior studies have indicated that the return and volatility of each market are correlated and that housing prices will co-move with economic proxies.

However, although previous studies have already discussed the ripple effect or co-movement between housing prices, knowledge about this dynamic relationship is still limited. These studies do not address the time-varying correlation in regional housing prices or the forces that drive this correlation. Therefore, our paper aims to fill this gap by using the copula method to estimate the dynamic correlation between each of the two markets. Using the Federal Housing Finance Agency index from 1995Q1 to 2012Q4, we select ten metropolitan statistical areas (MSAs) in three regions to compare. These regions include Boston, New York, Philadelphia, and Washington, D.C. in the Eastern region; Los Angeles, San Diego, and San Francisco 
in the Western region; and Chicago, Detroit, and Cleveland in the Great Lakes region.

Furthermore, we attempt to explore the determinants of housing price correlations. Based on the previous literature, we hypothesize two mechanisms that explain the connection between regional housing prices. First, the migration hypothesis predicts that less correlation, or larger differences in regional economic conditions, should be positively related to the correlation of housing prices because residents are more likely to move to MSAs that have cheaper housing prices (Meen 1999; Miao et al. 2011; Gray 2012). Second, the comovement hypothesis, by contrast, expects that a lower correlation, or a larger difference in regional economic conditions, should be negatively related to the correlation of housing prices because stronger co-movement in a regional economy will trigger the correlation of housing prices (Meen 1999; Zhu et al. 2013; Yunus, Swanson 2013; Kallberg et al. 2014).

This paper makes the following contributions to the literature. First, Miao et al. (2011) and Zhu et al. (2013) show the interdependence of returns, idiosyncratic risks, and volatility on the basis of a static correlation, which supposes that the relationship between markets remains unchanged over decades. However, conditioned on stable migration ability, economic co-movement should produce a wave over time rather than continuation at a static level. With dynamic correlation coefficients, we can more effectively describe the dynamic patterns of the interaction of prices. Our results show that the interaction of prices has produced waves over the last two decades. We also find that the interactions between markets with weak geographic connections were relatively weak.

Second, we indicate that the interaction of housing prices between some markets suddenly dropped before the subprime crisis. Compared with studies showing that the interaction of housing prices increased during the last decades (Yunus, Swanson 2013; Kallberg et al. 2014) or became stronger after the subprime crisis (Zhu et al. 2013), this study is the first to indicate that the interaction of prices substantially drops before a housing bust. We further show that the inconsistency of bust timing might be the reason for a substantial drop in the housing price correlation at that point.

Third, we test whether a migration or comovement mechanism dominates the interaction of housing prices. Because Meen (1999) indicates that there are four potential factors driving the interaction of housing prices, studies have supported the hypotheses that either the migration (Miao et al. 2011; Gray 2012; Sinai, Souleles 2013) or co-movement mechanism (Zhu et al. 2013; Yunus, Swanson 2013; Kallberg et al. 2014) affects the interaction of regional housing prices. We regress the time-varying dynamic correlations on the major economic variables, showing that the migration (co-movement) mechanism dominates the Eastern region (Western region, Great Lakes region, and between regions). In addition, in markets with only a weak connection, the economic comovement mechanism still induces the interaction of housing prices.

Finally, we also contribute to the literature regarding the ripple effect. Most studies of the ripple effect attempt to test the long-run convergence of the ripple effect (Cook 2003, 2005; Holmes, Grimes 2008; Gray 2012) or verify the ripple effect in other countries (Chien 2010; Lee, Chien 2011; Balcilar et al. 2013; Lean, Smyth 2013; Liao et al. 2014). ${ }^{1}$

Although we do not provide results of testing the process of the ripple effect, our results show that adjacent MSAs do indeed have a dynamic interaction in terms of housing prices. For instance, our copula method may provide a new way to test the mechanism of the ripple effect in the UK, an issue that has not yet been tested in the literature.

This paper proceeds as follows. Section 2 organizes the prior literature and describes our hypotheses. Section 3 introduces the methodology and data of this paper. Section 4 discusses the empirical results. Section 5 presents the robustness test. Section 6 provides conclusions.

\section{LITERATURE REVIEW}

\subsection{The interaction of regional housing prices}

\subsubsection{Ripple effect}

According to Meen (1999), the ripple effect is a distinct spatial pattern in the housing market. Housing prices first rise in one city, then spread to an adjoining city, and then spread further out to the next city, until this ripple reaches the borders of the country. Meen (1999) reviews the literature and proposes four possible explanations for the ripple effect: Migration, equity transfer, limited spatial arbitrage, and spatial patterns in the

\footnotetext{
${ }^{1}$ Due to space limitations, we do not discuss the latter strand of literature in this paper.
} 
determinants of housing prices. ${ }^{2}$ Following Meen (1999), follow-up papers tried to test the long-run convergence of the ripple effect (Cook 2003, 2005; Holmes, Grimes 2008; Gray 2012). Among these papers, Gray (2012) uses region-level data from Britain to analyze the pattern of the ripple effect, showing the dynamic patterns of the ripple effect in Britain. For instance, his results imply that the spatial spillover of housing price growth is unlikely to work on interlocked markets suffering from obstacles to commuting and migration.

\subsubsection{Co-movement}

Alternatively, another group of papers discusses the interaction of housing prices. Miao et al. (2011) analyze spatial dependences across MSAs, indicating that both information diffusion and population migration might be potential sources of these dependences. Zhu et al. (2013) highlight the importance of economic interdependence, indicating that regional interdependence during the subprime period obviously increases. Yunus and Swanson (2013) further support the premise that the convergence among MSAs substantially increased over time and more so after the housing bubble burst in the latter part of 2006. Kallberg et al. (2014) investigate the raw and excess co-movement among MSAs between 1992 and 2008, showing that the interdependence of the returns of U.S. residential real estate increased earlier than the financial crisis. Thus, there might have been co-movements among regional markets earlier than we assumed.

\subsection{How do these determinants affect the relationship between regional housing prices?}

To sum up the findings of the previous literature, the relationship between adjacent housing markets is largely driven by the co-movement of housing price determinants (Meen 1999; Zhu et al. 2013; Yunus, Swanson 2013; Kallberg et al. 2014) and population migration (Meen 1999; Miao et al. 2011; Gray 2012; Sinai, Souleles 2013). Based on these findings, we posit the following two hypotheses. First, the migration hypothesis predicts that less

\footnotetext{
${ }^{2}$ Sinai and Souleles (2013) provide a strong linkage for the relationship between migration activity and housing price correlation. Since households face uncertain sale prices for both their current and future houses, positively covarying prices between MSAs can reduce the risk posed to the moving decision (i.e., households do not independently face the price risks of the current and future houses). Thus, households tend to move between highly correlated MSAs, increasing the correlations in house prices across MSAs.
}

correlation of regional economic conditions should enhance the connection between housing prices because residents will move to other MSAs with cheaper housing prices. Second, the co-movement hypothesis, by contrast, expects that less correlation of economic conditions would decrease the connection between housing prices because weaker co-movement of regional variables should reduce the connection between housing prices. Based on these two hypotheses, we discuss the potential effects of each determinant on housing price relationships in more detail, as follows.

\section{Unemployment rates}

From the perspective of population migration, less correlation of unemployment rates should increase the correlation of housing prices because MSAs with lower unemployment rates have higher possibilities of immigration and this immigration will transfer housing demand from adjacent MSAs, leading to increases in housing prices. By contrast, from the perspective of determinant co-movement, less correlation of unemployment rates implies weaker co-movement of price determinants. When the price determinants have a weaker connection, we should expect, based on the co-movement hypothesis, that less correlation of unemployment rates induces lower correlation of housing prices.

\section{Construction permits}

Less correlation of construction permits implies an inconsistent housing supply. Residents living in MSAs with low levels of construction permits may immigrate to MSAs with relatively high levels of construction permits because these areas have more empty houses and lower housing prices. From the perspective of the migration hypothesis, less correlation of construction permits should induce a higher correlation of housing prices. However, when there is a decrease in the co-movement of the housing supply, the trends in housing prices might be much different. Thus, based on the comovement hypothesis, less correlation of construction permits induces lower correlation of housing prices.

\section{Personal income}

When there is less correlation of personal income between MSAs, residents living in high-income MSAs have an incentive to move to low-income MSAs because they offer cheaper housing and more choices. Because the migrating purchasers bring greater buying power, low-income MSA housing prices will go up and enhance the connection between housing prices. Based on the migration 
hypothesis, less correlation of personal income causes greater interaction in housing prices. From the contrary view of the co-movement hypothesis, less correlation of personal income implies weaker co-movement of economic conditions, and we would expect less interaction from housing prices.

\section{Population}

From the perspective of the migration hypothesis, less correlation of the population means a greater difference in housing demand, and residents living in high-demand MSAs might move to MSAs with lower housing demand because they offer more housing choices and lower housing prices. When migration activities increase, the interaction of housing prices should be stronger. Based on the migration hypothesis, less correlation of the population should predict a higher correlation of housing prices. By contrast, from the perspective of the co-movement hypothesis, less correlation of the population implies weaker co-movement of demographic conditions, and we should expect a lower interaction of housing prices.

\section{RESEARCH DESIGN AND DATA}

\subsection{Empirical design}

This paper employs the following steps. We first conduct a Phillips-Perron unit root test to examine the stationarity of the housing price index (Phillips, Perron 1988). We then apply the copula method to obtain the dynamic correlation coefficients between each MSA's economic variables, such as housing prices and other regional factors, and we analyze the changes in correlation between MSA housing prices. Thus, for each pair of MSAs (e.g., Boston and New York), we estimate a series of dynamic correlation coefficients for each regional variable during the full sample period. ${ }^{3}$ Finally, we use the dynamic correlation coefficients as dependent variables. We employ the following OLS model to examine how the determinants of regional housing prices affect the correlation between MSAs.

$$
\begin{aligned}
& \rho(H P)_{x y, t}=\rho(U E R)_{x y, t}+\rho(C P)_{x y, t}+\rho(I N C O M E)_{x y, t}+ \\
& \rho(P O P)_{x y, t}+M R_{t}+G D P_{t}+C P I_{t}+C R I S I S+\varepsilon_{t},
\end{aligned}
$$

where: $\rho(X)_{x y, t}$ is the dynamic correlation coefficients between $\mathrm{X}$ variable of $\mathrm{x}$ city and those of $\mathrm{y}$

${ }^{3}$ Because we employ the quarterly data from 1995Q1 to 2012Q4, we get a total of 72 observations of dynamic correlation coefficients for each regional variable between each pair of MSAs. city; $U E R$ is unemployment rates; $C P$ is construction permits; INCOME is personal income; $P O P$ is regional population; $M R$ is fixed mortgage rates; $G D P$ is gross domestic product; $C P I$ is consumer price index; and CRISIS is a dummy variable of the subprime period, which equals one when time $t$ is located in the subprime period and zero otherwise.

We use several macroeconomic variables such as mortgage rate, GDP, and consumer price index as control variables in our model. We also follow the definition of Zhu et al. (2013) to construct a dummy variable of the subprime period, which is between 2007Q1 and 2010Q4.

In addition, we discuss the determinants of the correlation between MSAs both in the intra-region and inter-region contexts. In the intra-region context, we pool the dynamic correlation coefficients between the regional variables of each pair of MSAs in the same region, and we then employ the regression shown in Model (1). Thus, we obtain more observations in our regression models (e.g., there are six pairs of MSAs that can calculate the dynamic correlation coefficients in the Eastern region, so we have a total of 432 observations in the Eastern region). ${ }^{4}$ In the inter-region context, we only employ the pool regression model on leading MSAs (i.e., New York, Los Angeles, and Chicago), so dynamic correlation coefficients are calculated only between leading MSAs.

We also employ the difference in regional economic variables as a robustness test for our study. In a departure from Model (1), we use the difference in regional economic variables instead of dynamic correlation coefficients as independent variables in Model (2).

$$
\begin{aligned}
& \rho(H P)_{x y, t}=\left(U E R_{x}-U E R_{y}\right)_{t}+\left(C P_{x}-C P_{y}\right)_{t}+ \\
& \left(I N C O M E_{x}-I N C O M E_{y}\right)_{t}+\left(P O P_{x}-P O P_{y}\right)_{t}+ \\
& M R_{t}+G D P_{t}+C P I_{t}+C R I S I S+\varepsilon_{t},
\end{aligned}
$$

where: regional independent variables are the difference in economic conditions, e.g., $\left(U E R_{x}-U E R_{y}\right)$ is the difference in the unemployment rate between $\mathrm{x}$ city and $\mathrm{y}$ city. To reflect the difference in economic conditions, we use the absolute value of all regional difference variables, and we also use the logarithm form of the continuous variables to avoid the scale problem.

\footnotetext{
${ }^{4}$ Although we may suffer from the problem of low frequency of housing price data, we use pool regression instead of rolling regression because the latter might produce a spurious regression with artificial persistence (Ferson et al. 2008).
} 


\subsection{Methodology}

This paper applies the copula method to obtain the dynamic correlation and analyze the trends in correlation between MSA housing prices; the copula method can capture time-varying correlations, particularly in the tail dependence, which a linear correlation model fails to do (Patton 2006a). According to Sklar (1959), any bivariate CDF (or ndimensional distribution) can be decomposed into two parts, the marginal distribution functions and the copula functions, the functions describing the dependence part of the distribution. In particular, for any random variables $\mathrm{y}_{1, \mathrm{t}}$ and $\mathrm{y}_{2, \mathrm{t}}$ with marginal CDFs $\mathrm{F}_{1}\left(\mathrm{y}_{1, \mathrm{t}}\right)$ and $\mathrm{F}_{2}\left(\mathrm{y}_{2}, \mathrm{t}\right)$, the values produced by CDFs will follow a uniform distribution regardless of the functional forms of the CDFs. Thus, the following copula function $\mathrm{C}($.), which connects the two CDFs, exists.

$$
\mathrm{F}\left(\mathrm{y}_{1, \mathrm{t},} \mathrm{y}_{2, \mathrm{t}}\right)=\mathrm{C}\left(\mathrm{F}_{1}\left(\mathrm{y}_{1, \mathrm{t}}\right), \mathrm{F}_{2}\left(\mathrm{y}_{2, \mathrm{t}}\right)\right)
$$

where: the copula function $\mathrm{C}($.) estimates the dependence of these two CDFs, i.e., the function $\mathrm{C}($.) yields the joint distribution of function $\mathrm{F}($.). If the marginal CDFs are continuous, the corresponding copula in Equation (3) is unique.

The copula is a convenient tool to integrate bivariate distributions even when the distributions are unknown or extremely complex..$^{5}$ Additionally, there is concurrently a growing application of the time-varying copula method in housing market research, which shows that the copula is a decent tool for modeling housing prices (Zimmer 2012, 2015). Zimmer (2012) indicates that jointly related asset prices may exhibit departures from normality, particularly in the tails, and he explores the housing price connection during the financial crisis using various copula specifications. Zimmer (2015) further employs the copula method in the multivariate GARCH model to verify the dynamic correlations between housing prices in four U.S. cities.

However, a potential problem of the copula method is that it is difficult to know how the marginal distribution functions are related (Coval et al. 2009). Furthermore, the joint distribution will be mischaracterized, perhaps strongly so, if an incorrect copula is chosen. In this paper, we select the Gaussian copula and Student's t copula to calculate the Akaike information criterion (AIC) and Bayesian information criterion (BIC) coefficients

\footnotetext{
${ }^{5}$ For a discussion of the literature and application of the copula-based method for economic and financial data, please refer to Patton (2006a, 2006b, 2012).
}

to determine which model is appropriate for the data. ${ }^{6}$ From the unreported results, the Gaussian copula seems to be more suitable than Student's t copula, so we apply the Gaussian copula to calculate the dynamic correlation between MSA housing prices. ${ }^{7}$

\subsection{Data description}

We use several data sources. The basic dataset we use in this paper is the quarterly seasonally adjusted Federal Housing Finance Agency (FHFA) index from 1995Q1 to 2012Q4. The construction of the FHFA index relies on a repeat sales valuation approach, which is similar to but somewhat different from the Case-Shiller Monthly House Price (CS) Indices. Compared with the CS index, the FHFA index has several advantages, as follows: first, the FHFA index began in 1975, which is earlier than the CS index, which began in 1987. Second, the FHFA index is weighted by the number of households and suffers less from the bias of market capitalization, as a result. Third, the FHFA index has broader geographic coverage. Finally, and most importantly, the FHFA index has regional-level data, while the CS index has data for only 20 cities and only at the national level (Yunus, Swanson 2013).

We select MSAs based on the following procedure. We first select the MSAs used in the prior literature as our potential targets, which includes 16 MSAs (Miao et al. 2011; Gupta, Miller 2012; Kallberg et al. 2014). Because the copula method can produce only one set of dynamic correlation coefficients between two markets, the inclusion of too many MSAs in our sample will mar the results. Thus, we further select the final MSAs using two criteria. First, we select MSAs that have a larger population in each region based on the data of the United States Census Bureau, as larger MSAs should be relatively influential. In this step, we include some MSAs that were not used in the prior literature, such as Detroit, as the FHFA index has broader coverage than the CS index.

Next, we employ MSAs that have stronger geographic connections with each other according to the literature (Gray 2012). Because the main goal of this paper is to examine the dynamic correlation between MSAs and its determinants, we

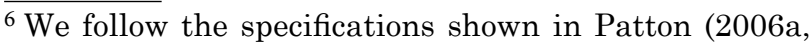
2006b) and Vogiatzoglou (2010) to estimate the dynamic Gaussian and Student's t copula.

7 To save space, we do not report the results of model selection, but the results are available upon request.
} 
select MSAs that do not suffer from the problem of geographical independence. Therefore, to maintain a sufficient number of targets to compare and maintain the geographical dependence of each MSA in our paper, we select 10 MSAs from different regions to examine the dynamic relationship between them. We select Boston, New York, Philadelphia, and Washington, D.C. as representatives of the Eastern region; Los Angeles, San Diego, and San Francisco as representatives of the Western region; and Chicago, Detroit, and Cleveland as representatives of the Great Lakes region.

In addition, we collect several important determinants of regional housing prices that have been supported by prior studies. We obtain unemployment rates from the Bureau of Labor Statistics (Johnes, Hyclak 1999; Saks 2008). The U.S. Bureau of the Census provides a source that compiles construction permits since January 1995 (Case, Mayer 1996; Mikhed, Zemcik 2009; Zhu et al. 2013). Personal income and population data are from the Bureau of Economic Analysis (Mankiw, Weil 1989; Swan 1995; Potepan 1996; Bischoff 2012; Yunus, Swanson 2013). On the national level, we obtain gross domestic product (GDP) data from the U.S. Bureau of the Census. The consumer price index (CPI) is from the International Monetary Fund. The 30-year fixed mortgage rate data are from the mortgage interest rate survey of HSH.com. Unemployment rates, mortgage rates, and construction permits are monthly data and are transformed to the quarterly level by averaging the numbers of each month in each quarter.

\section{EMPIRICAL RESULTS}

\subsection{Trends in housing prices and stationarity}

Table 1 briefly summarizes the mean values and standard deviations of regional factors for different MSAs, showing the heterogeneity of each MSA and region. For example, the average house price index is 181.27 in the Western region, but is 131.19 in the Great Lakes region, indicating that the strength of housing markets is different across regions. Among the $10 \mathrm{MSAs}$, residents living in New York are the wealthiest, but their house price index ranking is only $5^{\text {th }}$ out of our 10 MSAs, which may result from the higher number of housing permits in New York. Additionally, MSAs in the Eastern region have, on average, the largest populations among the three regions, implying relatively active immigration activities in the Eastern region. Finally, MSAs in the Great Lakes region have the lowest house price index and relatively worse economic conditions compared with the other regions.

Next, Figure 1 illustrates the time trends for the housing prices of our ten MSAs. In the Eastern region, Boston had the sharpest increase in housing prices until 2006Q1. Later, Washington's housing market rapidly rose during 2005Q1 to 2006Q4, experiencing a $24 \%$ increase during this period. By contrast, Philadelphia had a more steady increase and experienced less shock from the financial crisis. In the Western region, all three MSAs had much sharper increasing trends than other MSAs, but they also sustained the severest shocks from the financial crisis. For example, the Los Angeles house price was 338.45 in 2006Q4 and 230.02 in

Table 1. Summary statistics of each MSA

\begin{tabular}{|c|c|c|c|c|c|c|c|c|c|c|c|c|}
\hline & \multicolumn{2}{|c|}{$\begin{array}{l}\text { House price } \\
\text { index }\end{array}$} & \multicolumn{2}{|c|}{$\begin{array}{l}\text { Unemployment } \\
\text { rate }\end{array}$} & \multicolumn{2}{|c|}{ Mortgage rate } & \multicolumn{2}{|c|}{$\begin{array}{l}\text { Personal income } \\
\text { (millions) }\end{array}$} & \multicolumn{2}{|c|}{$\begin{array}{l}\text { Population } \\
\text { (thousands) }\end{array}$} & \multicolumn{2}{|c|}{ Housing permits } \\
\hline & Mean & StD. & Mean & StD. & Mean & StD. & Mean & StD. & Mean & StD. & Mean & StD. \\
\hline \multicolumn{13}{|c|}{ Panel A: Eastern region } \\
\hline Boston & 175.80 & 64.39 & 5.67 & 1.58 & 6.53 & 1.56 & 183,762 & 57,062 & 4,370 & 149 & 118,201 & 45,632 \\
\hline New York & 166.64 & 63.18 & 6.54 & 1.61 & 6.60 & 1.60 & 774,912 & 228,328 & 18,793 & 712 & 300,967 & 207,344 \\
\hline Philadelphia & 152.88 & 52.83 & 5.84 & 1.48 & 6.44 & 1.48 & 207,932 & 61,584 & 5,729 & 172 & 156,061 & 49,997 \\
\hline Washington, D.C. & 161.32 & 62.89 & 4.09 & 1.14 & 6.57 & 1.60 & 221,049 & 81,802 & 4,957 & 511 & 283,004 & 89,980 \\
\hline \multicolumn{13}{|c|}{ Panel B: Western region } \\
\hline Los Angeles & 178.70 & 75.25 & 7.83 & 2.39 & 6.61 & 1.61 & 414,290 & 118,408 & 12,285 & 541 & 234,399 & 129,674 \\
\hline San Diego & 178.61 & 74.46 & 5.96 & 2.39 & 6.62 & 1.61 & 99,896 & 118,408 & 2,834 & 541 & 144,243 & 66,912 \\
\hline San Francisco & 186.49 & 74.51 & 5.74 & 1.81 & 6.68 & 1.59 & 190,953 & 61,217 & 4,082 & 201 & 248,512 & 111,269 \\
\hline \multicolumn{13}{|c|}{ Panel C: Great Lakes region } \\
\hline Chicago & 137.62 & 38.23 & 6.63 & 1.90 & 6.65 & 1.54 & 322,910 & 87,517 & 9,024 & 396 & 411,491 & 210,055 \\
\hline Detroit & 133.91 & 34.13 & 8.64 & 3.11 & 6.56 & 1.60 & 141,887 & 29,071 & 4,380 & 69 & 184,390 & 107,844 \\
\hline Cleveland & 122.05 & 21.03 & 6.11 & 1.51 & 6.52 & 1.54 & 68,228 & 14,174 & 2,120 & 30 & 76,236 & 33,047 \\
\hline
\end{tabular}


2009Q3, which is a $32 \%$ decrease during that period. As opposed to other regions, the three MSAs in the Great Lakes region experienced trends that were much different from each other. Detroit rose first, and then Chicago rose later until 2007Q4, but Cleveland showed relatively steady trends during this period.

To understand the interaction of housing prices between regions, we also test the dynamic relationship between leading MSAs. We select New York, Los Angeles, and Chicago as representative MSAs from the Eastern, Western, and Great Lakes regions, respectively. According to Figure 1, the trends in house price indices are similar between New York and Chicago, whereas Los Angeles has relatively sharper increasing trends, but the re- verse power of its bubble bursting is also stronger than other leading MSAs. In sum, the results show that housing markets will generally co-move with other markets, but the trends are slightly different because of the different timing of bubbles bursting and resilience in each MSA.

To examine the stationarity of the housing price indices in ten MSAs, we employ the conventional Phillips-Perron unit root test and report the results in Table 2. We test three types of time series in the table. Based on the results in Table 2, all the house price indices in our ten MSAs are not stationary in level value. However, after taking the first difference of the house price index, the results show that most indices are stationary, and the house price indices in ten MSAs should follow an I (1) process.
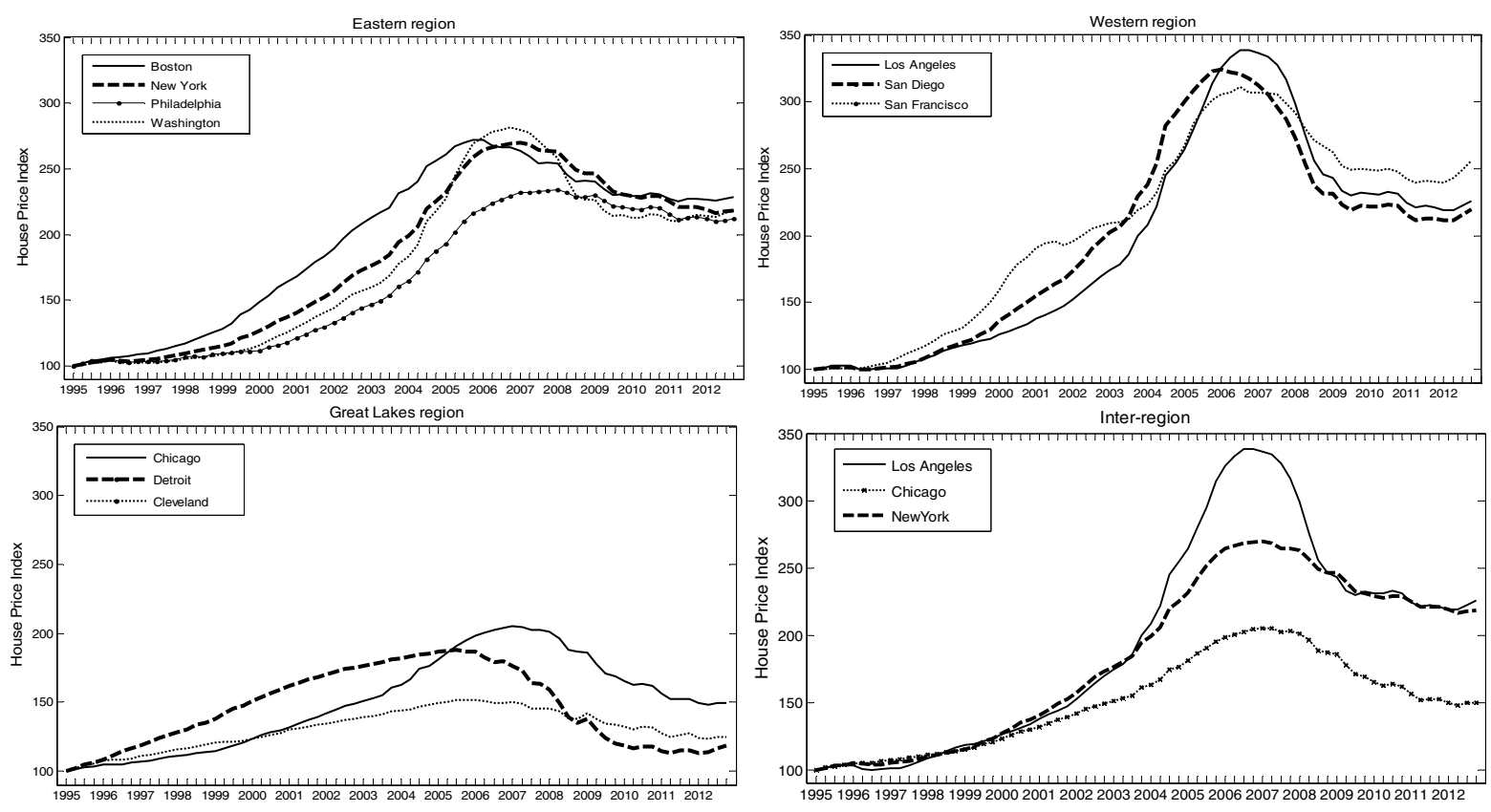

Fig. 1. Time trends of ten MSAs' house price indices

Table 2. Phillips-Perron unit root tests of ten MSAs house price index

\begin{tabular}{|c|c|c|c|c|c|c|}
\hline \multirow[t]{2}{*}{ Type of P-P test } & \multicolumn{2}{|c|}{ Without intercept and trend } & \multicolumn{2}{|c|}{ Without intercept } & \multicolumn{2}{|c|}{ With intercept and trend } \\
\hline & Level & First difference & Level & First difference & Level & First difference \\
\hline Boston & 1.1393 & $-3.2110^{* * *}$ & -0.7383 & $-3.6110^{* * * *}$ & -1.1374 & $-3.6180^{* *}$ \\
\hline New York & 0.9625 & $-2.5840^{* *}$ & -0.7317 & $-2.8400^{*}$ & -1.3455 & -2.8320 \\
\hline Philadelphia & 1.6494 & $-2.5550^{* *}$ & -0.3891 & $-3.2900^{* *}$ & -1.5052 & $-3.2710^{*}$ \\
\hline Washington, D.C. & 0.7412 & $-2.6440^{* * *}$ & -0.8334 & $-2.7660^{*}$ & -1.5560 & -2.7470 \\
\hline Los Angeles & 0.2194 & $-2.5390^{* *}$ & -1.0016 & -2.5800 & -1.5482 & -2.5650 \\
\hline San Diego & 0.3463 & $-2.7970^{* * *}$ & -1.0365 & $-2.8720^{* *}$ & -1.2520 & -2.8570 \\
\hline San Francisco & 1.0077 & $-2.6810^{* * *}$ & -0.7045 & $-2.9350^{* *}$ & -1.4729 & -2.9140 \\
\hline Chicago & 0.7178 & $-3.4690^{* * * *}$ & -1.3725 & $-3.1690^{* *}$ & -0.2090 & $-3.4120^{*}$ \\
\hline Detroit & 0.2364 & $-4.2070^{* * * *}$ & -1.4685 & $-4.2520^{* * * *}$ & -0.1894 & $-4.3630^{* * * *}$ \\
\hline Cleveland & 1.3215 & $-6.3080^{* * * *}$ & -2.4823 & $-6.6830^{* * *}$ & 1.1968 & $-7.8530^{* * *}$ \\
\hline
\end{tabular}

Note: ${ }^{*}$ and $* *$ and $* * *$ denote the rejection of null hypothesis at $10 \%$ and $5 \%$ and $1 \%$ significance level. 


\subsection{Static correlation in each region}

We calculate the traditional correlation between each MSA as a comparison with time-varying dynamic correlation. As indicated by the results in Table 3, most pairs in the Eastern and Western regions exhibit high correlation of house price indices. By contrast, the average correlation of the Great Lakes region is 0.73 , which is much lower than the other regions. Gray (2012) and Gupta and Miller (2012) show that weak interaction between housing markets might be attributed to weak commuting ability. Because the geographic connection of MSAs in the Great Lakes region is relatively weak, the lower correlation in the Great Lakes region could partly be driven by its commuting problem.

In terms of inter-region context, Panel B in Table 3 shows that the leading MSAs in different regions are highly correlated with other leading MSAs, in which correlation, on average, is 0.89 . For instance, the static correlation of housing prices between New York and Chicago is 0.94, showing that these two housing markets have especially high co-movement, even though they are not close to each other.

Table 3. Pearson correlation coefficients of house price index in each region

\begin{tabular}{|c|c|c|c|}
\hline \multicolumn{4}{|c|}{ Panel A: Intra-region } \\
\hline \multicolumn{4}{|c|}{ Panel A.1: Correlation in the Eastern region } \\
\hline & Boston & $\begin{array}{l}\text { New } \\
\text { York }\end{array}$ & $\begin{array}{ll}\text { Phila- } & \text { Washing- } \\
\text { delphia } & \text { ton }\end{array}$ \\
\hline Boston & 1 & & \\
\hline New York & 0.8604 & 1 & \\
\hline Philadelphia & 0.6769 & 0.9084 & 1 \\
\hline Washington, D.C. & 0.7536 & 0.9121 & $0.8494 \quad 1$ \\
\hline \multicolumn{4}{|c|}{ Panel A.2: Correlation in the Western region } \\
\hline & $\begin{array}{l}\text { Los An- } \\
\text { geles }\end{array}$ & $\begin{array}{l}\text { San } \\
\text { Diego }\end{array}$ & San Francisco \\
\hline Los Angeles & 1 & & \\
\hline San Diego & 0.9110 & 1 & \\
\hline San Francisco & 0.8498 & 0.8393 & 1 \\
\hline \multicolumn{4}{|c|}{ Panel A.3: Correlation in the Great Lakes region } \\
\hline & Chicago & Detroit & Cleveland \\
\hline Chicago & 1 & & \\
\hline Detroit & 0.6730 & 1 & \\
\hline Cleveland & 0.7388 & 0.7800 & 1 \\
\hline \multicolumn{4}{|c|}{ Panel B: Inter-region } \\
\hline & $\begin{array}{l}\text { New } \\
\text { York }\end{array}$ & $\begin{array}{l}\text { Los } \\
\text { Angeles }\end{array}$ & Chicago \\
\hline New York & 1 & & \\
\hline Los Angeles & 0.8849 & 1 & \\
\hline Chicago & 0.9417 & 0.8603 & 1 \\
\hline
\end{tabular}

\subsection{What are the time-varying relationships between regional housing prices?}

Figure 2 reports the dynamic correlation of the housing price index between each pair of MSAs. For comparison, we also plot the static correlation value as a dotted line. The results of Figure 2 show that most MSAs have a high connection with other MSAs, but the MSAs in the Great Lakes region have, in general, relatively weaker connections. For instance, an instructive finding in the time trends of each dynamic correlation is that most correlation coefficients dropped off during 2006. Zhu et al. (2013) show that interconnections across markets became stronger during the subprime crisis. Kallberg et al. (2014) indicate that co-movement among MSAs increased considerably from 1992 to 2008. No paper has indicated that co-movements among markets suddenly dropped before the subprime crisis.

A potential reason for the sudden drop in correlation might be the inconsistent trends in housing prices. According to the price trends in Figure 1, all four Eastern MSAs had stable increasing trends before 2006Q1. In 2006Q1, Boston housing prices started decreasing, but the other three housing markets continued increasing, which caused a sudden drop in connection. This phenomenon can also be observed in the connection between Los Angeles and San Diego, which faced an obviously inconsistent trend in 2006. After 2007, because most of the housing markets suffered from the financial crisis, the correlation again returned to the precrisis level.

Figure 2 also reports the dynamic correlation of house price indices between leading MSAs in each region. The results in Table 3 show that the correlation between leading MSAs has been high and stable during the past two decades, although the inconsistent reversed trends in 2007 and 2010 slightly decreased the high correlation between MSAs. In sum, the results show that time-varying correlation provides a clearer picture of the interaction of housing prices. For example, the dramatic waves of interaction between Chicago and Detroit are unobservable from the static correlations, and the substantial drop in the interaction of prices in 2006 is also unobservable from the static correlations. Thus, compared with the static correlations, time-varying correlation more effectively plots the interaction trends of prices.

Sinai (2012) mentions that the cross sectional variance of annual house price changes increases in booms and decreases in busts. Our findings, to 
Panel A: Dynamic copula method - Intra-region

Panel A.1: Dynamic copula method in the Eastern region
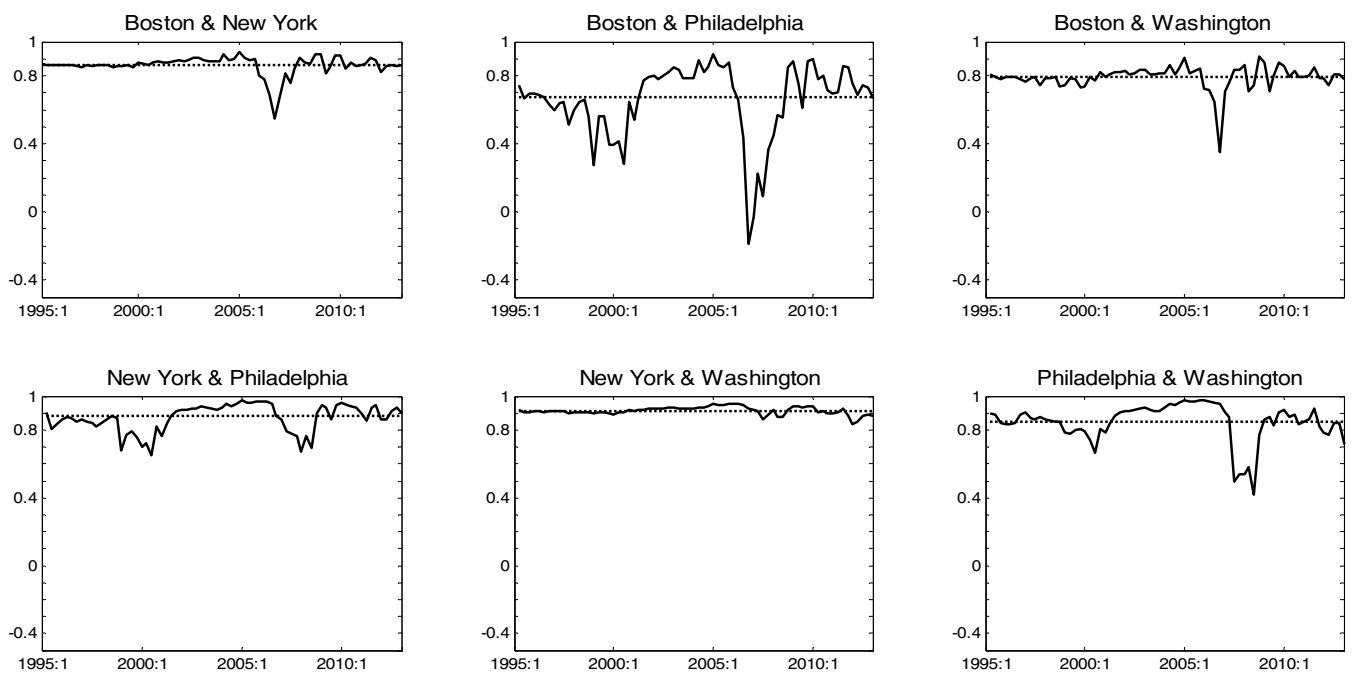

Panel A.2: Dynamic copula method in the Western region
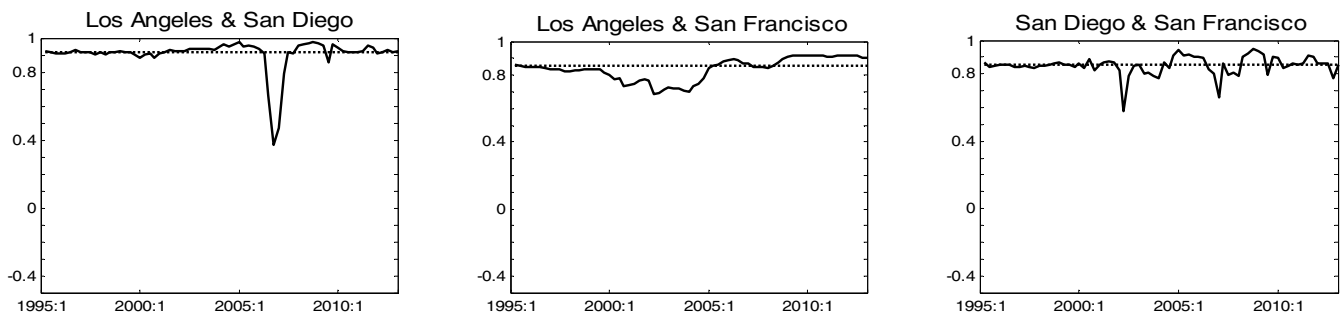

Panel A.3: Dynamic copula method in the Great Lakes region
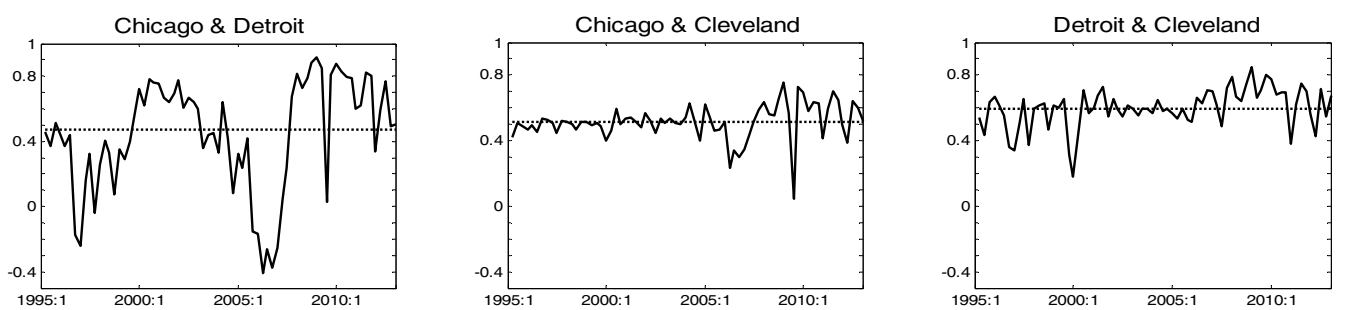

Panel B: Dynamic copula method - Inter-region
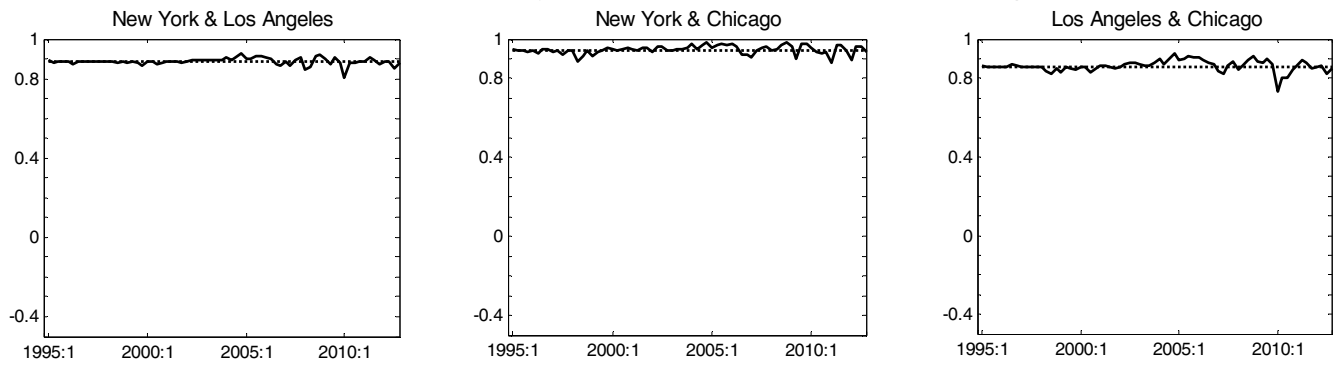

Note: This figure presents the Pearson static correlation (dotted line) and Copula time-varying dynamic correlation (solid line) in each pair of MSAs.

Fig. 2. Pearson correlation and copula dynamic correlation in each region

some extent, implement his results. Specifically, our results show that the increasing patterns in housing prices are different between MSAs in the boom period, which caused a slight drop in the dynamic correlation coefficients between housing prices. In addition, the inconsistent reversed timing in 2007 and 2010 may be the reason for the substantial drop in the housing price correlation between MSAs. Since the financial crisis, the patterns during the housing bust have been much more consistent, with the exception of MSAs in the Great Lakes region, implying that housing prices have become more synchronized since the crisis. 


\subsection{How do these underlying causes drive the connections in housing markets?}

\subsubsection{Intra-region}

To understand what sources drive connections in housing prices, we further regress the time-varying dynamic correlations calculated by the copula model on four important determinants of housing prices. According to Dolde and Tirtiroglu (2002), regional factors, rather than macroeconomic factors, should have a stronger effect on volatility shifts in regional housing prices, so we mainly discuss the effect of regional factors. To reflect the interaction between regional markets, we use the dynamic correlation of regional variables as a measure (Model 1). We separately report the regression results of each region in Table 4, and we discuss the findings based on the different expectations of the two hypotheses in Section 2.2.

\subsubsection{Unemployment rates}

The positive effect of unemployment rates shown in Table 4 indicates that MSAs in both the Western and Great Lakes regions are supported by the co-movement hypothesis and that MSAs in the Eastern region are not affected by the correlation of unemployment rates. Thus, the co-movement mechanism would be the main mechanism in the Western and Great Lakes regions, and the connection between MSAs in the Eastern region might be determined by other sources.

\subsubsection{Construction permits}

From the results, we can see that only the connection between MSAs in the Great Lakes region is positively related to the correlation of construction permits, and the other two regions do not exhibit a similarly significant relationship. In sum, consistent with the co-movement hypothesis, a higher correlation of construction permits indicates a higher connection between housing prices in the Great Lakes region.

\subsubsection{Personal income}

The results regarding personal income show that the migration hypothesis is supported in the Eastern region, but MSAs in the Western and Great Lakes regions are more reflective of the co-movement hypothesis. Thus, compared to the Eastern region, the connection in housing prices in the Western and Great Lakes regions is more likely triggered by economic co-movement.

\subsubsection{Population}

According to the results, we find that MSAs in both the Eastern and Western regions support the co-movement hypothesis, and the connection between housing markets in the Great Lakes region is more likely triggered by aspects of the migration hypothesis.

In conclusion, we find that the mechanism is slightly different in each region. The co-movement mechanism most likely determines the connection between housing markets in the Western and the Great Lakes regions. The connection between MSAs in the Eastern region, by contrast, has no obvious results as in the other regions. Because MSAs in the Great Lakes region should have weaker commuting ability, our results imply that their connection is more likely driven by the economic co-movement mechanism.

Table 4. Regressing housing price correlation on the correlation of regional factors - Intra-region

\begin{tabular}{|c|c|c|c|}
\hline & EAST & WEST & LAKE \\
\hline \multicolumn{4}{|c|}{ Regional variables } \\
\hline$\rho(U E R)_{x y}$ & 0.0205 & $0.1118^{* * *}$ & $0.3487^{* * *}$ \\
\hline \multirow{2}{*}{$\rho(C P)_{x y}$} & $(0.83)$ & $(3.58)$ & $(2.74)$ \\
\hline & 0.0161 & -0.0259 & $1.2379^{* * *}$ \\
\hline \multirow{2}{*}{$\rho(I N C O M E)_{x y}$} & $(0.55)$ & $(-1.17)$ & $(3.62)$ \\
\hline & $-2.1440^{* * *}$ & $0.6303^{* * *}$ & $35.1492^{* * *}$ \\
\hline \multirow{3}{*}{$\rho(P O P)_{x y}$} & $(-4.17)$ & $(7.53)$ & $(5.72)$ \\
\hline & $0.0889^{* * * *}$ & $0.0557^{* *}$ & $-1.2445^{* * *}$ \\
\hline & $(9.12)$ & $(2.53)$ & $(-5.80)$ \\
\hline \multicolumn{4}{|c|}{ Macroeconomic variables } \\
\hline \multirow[t]{2}{*}{$\mathrm{MR}$} & -0.0112 & -0.0023 & -0.0124 \\
\hline & $(-0.63)$ & $(-0.14)$ & $(-0.26)$ \\
\hline \multirow[t]{2}{*}{ GDP } & 0.0007 & -0.0009 & -0.0122 \\
\hline & $(0.31)$ & $(-0.45)$ & $(-2.06)$ \\
\hline \multirow[t]{2}{*}{ CPI } & -0.0007 & $0.0013^{* * *}$ & $-0.0022^{* *}$ \\
\hline & $(-1.61)$ & $(2.86)$ & $(-1.52)$ \\
\hline \multirow[t]{2}{*}{ CRISIS } & -0.0089 & -0.0070 & $0.1450^{* * *}$ \\
\hline & $(-0.55)$ & $(-0.45)$ & $(3.15)$ \\
\hline \multirow[t]{2}{*}{$\mathrm{C}$} & $2.9735^{* * *}$ & 0.0143 & $-33.8499^{* * *}$ \\
\hline & $(6.06)$ & $(0.17)$ & $(-5.73)$ \\
\hline $\mathrm{N}$ & 432 & 216 & 216 \\
\hline Adj. R-squared & 0.24 & 0.40 & 0.28 \\
\hline F-test & 17.43 & 18.44 & 11.53 \\
\hline
\end{tabular}

Note: EAST is the regression results of the Eastern region; WEST is the regression results of the Western region; LAKE is the regression results of the Great Lakes region. $\rho(X)_{x y, t}$ is the time-varying correlation coefficients between $\mathrm{X}$ variable of $\mathrm{x}$ city and those of y city; $U E R$ is unemployment rates; $C P$ is construction permits; INCOME is personal income; $P O P$ is regional population; $M R$ is fixed mortgage rates; $G D P$ is gross domestic product; $C P I$ is consumer price index; CRISIS is a dummy variable which equals one when time $t$ locates in the subprime period and zero otherwise. T-statistics are reported in parentheses; *, $* *$, and $* * *$ stand for significance at the $10 \%, 5 \%$, and $1 \%$ levels, respectively. 


\subsubsection{Inter-region}

Table 3 and Figure 2 both show that the housing prices of leading MSAs in each region are highly correlated with each other. We further test whether the interaction between leading MSAs is attributed to the migration or co-movement mechanism. Because each region is distant from the other, we should not expect migration activity between the leading MSAs. Hence, the economic co-movement mechanism would be the main force driving the interaction between housing prices in different regions. We test this hypothesis and report the results in column (1) of Table 5.

\subsubsection{Unemployment rates}

The results in Table 5 show that higher co-movement of unemployment rates between leading MSAs would decrease the correlation of housing prices. Contrary to our expectation, we do not find evidence from unemployment rates that supports the co-movement hypothesis.

\subsubsection{Construction permits}

Supporting the co-movement hypothesis, an increase in the correlation of construction permits will enhance the connection of housing prices. When the co-movement of the housing supply between regions is high, the connection of the housing prices will increase simultaneously.

\subsubsection{Personal income}

Consistent with our prediction, a correlation of personal income between regions has a positive effect on the correlation of housing prices. When different regions have high co-movement of housing demand, such as personal income, their housing price connection will be stronger. For instance, consistent with the findings of Ferreira and Gyourko (2011), the results also show that the effect of personal income is much stronger than other regional variables. A one percent increase in income correlation will induce a 3.5 percent increase in housing price correlation, which is much higher than other factors.

\subsubsection{Population}

Higher correlation of populations between leading MSAs also reinforces the connection of housing prices between these MSAs. The positive relationship between the correlation of population and that of housing prices supports our prediction. Economic co-movement would be the main force driving the co-movement of housing prices in different regions.
In sum, except for unemployment rates, all increases in correlations of construction permits, personal income, and population will enhance the connection of housing prices between leading MSAs. Consistent with our expectation, the connection of housing prices in different regions is mainly driven by co-movement forces, as migration activities are relatively difficult between regions.

Table 5. Determinants of housing price correlation Inter-region

$\frac{\text { Independent variable }}{\rho(V A R)_{x y} \quad\left(V A R_{x}-V A R_{y}\right)}$

(1) (2)

\begin{tabular}{lll}
\hline Regional variables & & \\
UER & $-0.0433^{* * *}$ & $-0.0066^{* * *}$ \\
& $(-2.28)$ & $(-3.74)$ \\
CP & $0.1443^{* * *}$ & 0.0022 \\
& $(10.78)$ & $(0.66)$ \\
INCOME & $3.5140^{* * * *}$ & $-0.1271^{* * *}$ \\
& $(5.57)$ & $(-5.26)$ \\
POP & $0.0340^{* * *}$ & $0.1544^{* * *}$ \\
& $(3.63)$ & $(9.29)$ \\
Macroeconomic variables & \\
MR & -0.0085 & -0.0056 \\
& $(-1.23)$ & $(-0.94)$ \\
GDP & 0.0008 & 0.0006 \\
CPI & $(0.89)$ & $(0.84)$ \\
& $0.0005^{* * *}$ & $0.0010^{* * *}$ \\
CRISIS & $(2.66)$ & $(4.13)$ \\
& -0.0054 & $0.0095^{* * *}$ \\
C & $(-0.85)$ & $(1.78)$ \\
& $-2.6560^{* * *}$ & $-0.5463^{* * *}$ \\
N & $(-4.28)$ & $(-6.50)$ \\
Adj. R-squared & 216 & 216 \\
F-test & 0.56 & 0.68 \\
\hline
\end{tabular}

Note: $\rho(V A R)_{x y, t}$ is the time-varying correlation coefficient between variables of $\mathrm{x}$ city and those of $\mathrm{y}$ city, and $\left(V A R_{x}-V A R_{y}\right)$ is the difference in regional factor. The definitions of the abbreviation are defined in Table 4. T-statistics are reported in parentheses; ${ }^{*}, * *$, and ${ }^{* * *}$ stand for significance at the $10 \%, 5 \%$, and $1 \%$ levels, respectively.

\section{ROBUSTNESS TESTS}

Subsequently, we use differences in regional variables as an alternative independent variable for retesting the results of Model 1. For comparison, we call this equation Model 2. Unlike the dynamic correlation between MSAs, substantial differences in economic conditions can reflect an incentive 
for migration (i.e., residents have an incentive to migrate because adjacent MSAs have cheaper housing prices or a greater number of housing choices). Thus, if the effect followed the migration hypothesis, we would expect greater differences in variables to cause a stronger interaction between housing prices because migration activities would increase.

By contrast, according to the co-movement hypothesis, a large difference in economic conditions between MSAs would narrow the economic co-movement between the MSAs and reduce the connection. On the basis of the co-movement hypothesis, we would predict a negative relationship between the differences in variables and the interaction of housing prices. We separately report the regression results of each region in Table 6 . We also report the inter-regional results in column (2) of Table 5 .

\subsection{Unemployment rates}

The results in Table 6 show that the difference in unemployment rates is positively related to the connection between MSAs in the Eastern and the Western regions, indicating that these two regions are driven by the migration hypothesis. By contrast, the negative effect of the difference in unemployment rates shows that the co-movement mechanism works in the Great Lakes region and between regions.

\subsection{Construction permits}

The results indicate that the difference in construction permits has a positive and negative effect in the Eastern and the Western regions, respectively, and no effect is found in the Great Lakes region. Thus, the migration mechanism works within the Eastern MSAs, whereas the co-movement mechanism is the main force in the Western region. From the results of our inter-region analysis, we do not find support for each mechanism based on the difference in construction permits between regions.

\subsection{Personal income}

Unlike other variables, the results of personal income are relatively weak in each region; we only find a negative effect on the interaction of housing prices in the Western region. Our results indicate that only MSAs in the Western region follow the co-movement hypothesis. Additionally, we also find evidence of the co-movement mechanism in the housing price correlation between leading MSAs.

\subsection{Population}

From the results in Table 6, the negative effect shows that MSAs in the Western region are driven by the co-movement hypothesis. However, a larger difference in population will enhance the connection between housing prices in the Eastern region. Therefore, the migration hypothesis still holds in the Eastern region. Moreover, the connection between MSAs in the Great Lakes region is not affected by the difference in population. Unlike the finding estimated by the dynamic correlation of population, the difference in population will increase the correlation of housing prices between leading MSAs and support the migration hypothesis.

In sum, migration forces are the main mechanism affecting the connection between MSAs in the Eastern region. Economic co-movement determines the connection between MSAs in the Western region. The connection between MSAs in the Great Lakes region is only affected by the

Table 6. Regressing housing price correlation on the difference in regional factors - Intra-region

\begin{tabular}{|c|c|c|c|}
\hline & EAST & WEST & LAKE \\
\hline \multicolumn{4}{|c|}{ Regional variables } \\
\hline$\left(U E R_{x}-U E R_{y}\right)$ & $\begin{array}{l}0.0121^{* * * *} \\
(4.12)\end{array}$ & $\begin{array}{l}0.0239^{* * * *} \\
(4.43)\end{array}$ & $\begin{array}{l}-0.0267^{* *} \\
(-1.97)\end{array}$ \\
\hline$\left(C P_{x}-C P_{y}\right)$ & $\begin{array}{l}0.0281^{* * *} \\
(4.66)\end{array}$ & $\begin{array}{l}-0.0379^{* * *} \\
(-2.83)\end{array}$ & $\begin{array}{l}-0.0697 \\
(-1.59)\end{array}$ \\
\hline$\left(\begin{array}{l}I N C O M E_{x}- \\
I N C O M E_{y}\end{array}\right)$ & $\begin{array}{l}-0.0113 \\
(-0.96)\end{array}$ & $\begin{array}{l}-0.0251^{*} \\
(-1.88)\end{array}$ & $\begin{array}{l}-0.0656 \\
(-0.48)\end{array}$ \\
\hline$\left(P O P_{x}-P O P_{y}\right)$ & $\begin{array}{l}0.0336^{* * *} \\
(5.68)\end{array}$ & $\begin{array}{l}-0.0141^{* *} \\
(-2.23)\end{array}$ & $\begin{array}{l}-0.1050 \\
(-1.36)\end{array}$ \\
\hline \multicolumn{4}{|c|}{ Macroeconomic variables } \\
\hline MR & $\begin{array}{l}-0.0046 \\
(-0.33)\end{array}$ & $\begin{array}{l}-0.0041 \\
(-0.24)\end{array}$ & $\begin{array}{l}-0.0385 \\
(-0.75)\end{array}$ \\
\hline GDP & $\begin{array}{l}-0.0012 \\
(-0.67)\end{array}$ & $\begin{array}{l}0.0019 \\
(0.90)\end{array}$ & $\begin{array}{l}-0.0100 \\
(-1.57)\end{array}$ \\
\hline CPI & $\begin{array}{l}-0.0002 \\
(-0.51)\end{array}$ & $\begin{array}{l}0.0006 \\
(1.07)\end{array}$ & $\begin{array}{l}0.0045^{* *} \\
(2.03)\end{array}$ \\
\hline CRISIS & $\begin{array}{l}0.0019 \\
(0.15)\end{array}$ & $\begin{array}{l}0.0405^{* *} \\
(2.57)\end{array}$ & $\begin{array}{l}0.0459 \\
(0.91)\end{array}$ \\
\hline $\mathrm{C}$ & $\begin{array}{l}0.2991^{* * *} \\
(5.38)\end{array}$ & $\begin{array}{l}1.3505^{* * *} \\
(14.57)\end{array}$ & $\begin{array}{l}2.6971^{* * *} \\
(4.25)\end{array}$ \\
\hline $\mathrm{N}$ & 432 & 216 & 216 \\
\hline Adj. R-squared & 0.48 & 0.27 & 0.16 \\
\hline F-test & 50.70 & 10.84 & 6.04 \\
\hline
\end{tabular}

Note: This table reports the regression results using the difference in regional factors as an independent variable, and the definitions of the abbreviation are defined in Table 4. T-statistics are reported in parentheses; *,**, and *** stand for significance at the $10 \%, 5 \%$, and $1 \%$ levels, respectively. 
co-movement of the labor market and other determinants have a weak effect on it. Consistent with the findings in Table 4, we show that the migration hypothesis works in the Eastern region, while the co-movement hypothesis works in the Western and the Great Lakes regions. From the results of analysis between regions, we also find that comovement forces are relatively stronger than migration activities.

To further organize our empirical results, we report and compare the results of our two models in Table 7. Generally, we can conclude the following findings from Table 7. First, in the Eastern region, the results of Model 2 clearly show that the migration mechanism determines the connection between MSAs in the Eastern region, whereas the results of Model 1 only support the migration mechanism from the perspective of personal income. Next, in the Western region, the results of both Model 1 and Model 2 provide strong evidence of the co-movement mechanism. Finally, the co-movement mechanism obtains relatively more support in the two models based on the results of the Great Lakes region and inter-region contexts. In sum, the results of the two models support the same mechanism in each region even though the results may be relatively weak in one of the models.

On the other hand, consistent with the findings of Ferreira and Gyourko (2011, 2012), we find that personal income significantly affects the interaction of housing prices, especially by the economic co-movement mechanism. Ferreira and Gyourko (2012) also show that the market booming first in Boston includes relatively low-income neighborhoods, implying that personal income may not be the demand shifter in the Eastern region. We find that the interaction of personal income indeed has a negative effect on the housing price connection only in the Eastern region, and this difference indicates that the migration mechanism should be the main force in the Eastern region.

In short, our results show that the connection between MSAs in the Eastern region generally follows the migration mechanism. The co-movement of regional economies, meanwhile, determines the connection between MSAs in the Western region, the Great Lakes region, and between regions. Therefore, the different forces indicated by the previous literature might work in the United States but in different regions. From the perspective of geography, our findings show that weak migration ability in the Great Lakes region, or inter-regionally, makes economic co-movement the major force interlinking housing prices (Gray 2012; Gupta, Miller 2012).

On the economic side, the relatively consistent trends in housing prices shown in Figure 1 strengthen the connection between housing prices in the Western region. When economic co-movement is relatively weak and the geographic link is stable, the migration mechanism again becomes the main force, as in the case of MSAs in the East-

Table 7. Regression results of alternative proxies

\begin{tabular}{|c|c|c|c|c|c|c|c|c|c|}
\hline & & \multicolumn{2}{|l|}{ EAST } & \multicolumn{2}{|l|}{ WEST } & \multicolumn{2}{|l|}{ LAKE } & \multicolumn{2}{|c|}{ INTER-REGION } \\
\hline & & Hypothesis & Sig. & Hypothesis & Sig. & Hypothesis & Sig. & Hypothesis & Sig. \\
\hline \multicolumn{10}{|l|}{ Model 1} \\
\hline UER & $\rho(U E R)_{x y}$ & Co-movement & & Co-movement & $* * * *$ & Co-movement & $* * * *$ & Migration & $* *$ \\
\hline $\mathrm{CP}$ & $\rho(C P)_{x y}$ & Co-movement & & Migration & & Co-movement & $* * *$ & Co-movement & $* * * *$ \\
\hline INCOME & $\rho(I N C O M E)_{x y}$ & Migration & $* * *$ & Co-movement & $* * *$ & Co-movement & $* * * *$ & Co-movement & $* * * *$ \\
\hline POP & $\rho(P O P)_{x y}$ & Co-movement & $* * *$ & Co-movement & $* *$ & Migration & $* * *$ & Co-movement & $* * * *$ \\
\hline \multicolumn{10}{|l|}{ Model 2} \\
\hline UER & $\left(U E R_{x}-U E R_{y}\right)$ & Migration & $* * *$ & Migration & $* * *$ & Co-movement & $* *$ & Co-movement & $* * *$ \\
\hline $\mathrm{CP}$ & $\left(C P_{x}-C P_{y}\right)$ & Migration & $* * *$ & Co-movement & $* * *$ & Co-movement & & Migration & \\
\hline INCOME & $\left(\begin{array}{l}I N C O M E_{x}- \\
I N C O M E_{y}\end{array}\right)$ & Co-movement & & Co-movement & * & Co-movement & & Co-movement & $* * * *$ \\
\hline POP & $\left(P O P_{x}-P O P_{y}\right)$ & Migration & $* * *$ & Co-movement & $* *$ & Co-movement & & Migration & $* * * *$ \\
\hline
\end{tabular}


ern region. From unreported results, we calculate the changes in the population of our 10 MSAs. We find that Washington, D.C. has relatively positive and large changes in population during our sample period, which may reflect the stronger migration activities in the Eastern region. However, other MSAs in the Eastern region do not have changes in population as large as those in the MSAs in the Western region.

\section{CONCLUSION}

This paper discusses the time-varying dynamic interaction of housing prices, using the copula method to calculate the dependent distribution of housing prices. The results show that there are indeed co-movement trends between housing prices and that the time-varying dynamic correlation can plot clearer results than traditional correlation. From the findings of dynamic correlation, inconsistency in price reversion causes a general drop in correlation in 2006. For instance, weaker correlation is found between the MSAs with weak commuting ability or geographic connections, such as MSAs in the Great Lakes region; this result supports the findings of the prior literature (Gray 2012; Gupta, Miller 2012).

To understand the underlying causes of housing price connections, we further employ two regression models. The regression results show that the co-movement mechanism most likely determines the connection between housing markets in the Western, the Great Lakes regions, and between regions. By contrast, the connections between MSAs in the Eastern region are driven by the migration mechanism. Because MSAs in the Great Lakes region should have relatively weaker commuting ability, our results imply that the co-movement of economic conditions might become the major force when the migration motive is weak.

However, one concern must be emphasized. Many forces can induce the interaction of housing prices, whereas the migration and economic co-movement mechanisms may not be the only interpretations explaining the housing price connection. For example, Leung and Teo (2011) built a dynamic stochastic general equilibrium model with two regions, showing that the differences in housing supply elasticity across regions can have nontrivial effects on regional differences in housing prices even when the two regions are identical and have no economic linkages between them. Dolde and Tirtiroglu (1997) indicate positive spatial information diffusion between neighboring towns in Connecticut and San Francisco, indicating that information diffusion may also link the housing prices in adjacent markets. Dolde and Tirtiroglu (2002) further find a significant inter-regional diffusion of volatility upsurges.

We only discuss the migration and the economic co-movement mechanisms because they find more support in the literature relative to other reasons, but we do believe that there are other possible interpretations for the housing price connection.

\section{REFERENCES}

Balcilar, M.; Beyene, A.; Gupta, R.; Seleteng, M. 2013. 'Ripple' effects in South African housing prices, Urban Studies 50(5): 876-894. https://doi.org/10.1177/0042098012458551

Bischoff, O. 2012. Explaining regional variation in equilibrium real estate prices and income, Journal of Housing Economics 21: 1-15. https://doi.org/10.1016/j.jhe.2011.11.002

Case, K. E.; Mayer, C. J. 1996. Housing price dynamics within a metropolitan area, Regional Science and Urban Economics 26: 387-407. https://doi.org/10.1016/0166-0462(95)02121-3

Chien, M. S. 2010. Structural breaks and the convergence of regional housing prices, Journal of Real Estate Finance and Economics 40: 77-88. https://doi.org/10.1007/s11146-008-9138-y

Cook, S. 2003. The convergence of regional housing prices in the UK, Urban Studies 40(11): 2285-2294. https://doi.org/10.1080/0042098032000123295

Cook, S. 2005. Detecting long-run relationships in regional housing prices in the UK, International Review of Applied Economics 19(1): 107-118. https://doi.org/10.1080/0269217042000312632

Coval, J.; Jurek, J.; Staord, E. 2009. The economics of structured Finance, Journal of Economic Perspectives 23: 3-25. https://doi.org/10.1257/jep.23.1.3

Dolde, W.; Tirtiroglu, D. 1997. Temporal and spatial information diffusion in real estate price changes and variances, Real Estate Economics 25(4): 539-565. https://doi.org/10.1111/1540-6229.00727

Dolde, W.; Tirtiroglu, D. 2002. Housing price volatility changes and their effects, Real Estate Economics 30(1): 41-66. https://doi.org/10.1111/15406229.00029

Ferreira, D. F.; Gyourko, J. 2012. Heterogeneity in neighborhood-level price growth in the U.S., 19932009, American Economic Review Papers and Proceedings 102(3): 134-140. https://doi.org/10.1257/ aer.102.3.134

Ferreira, D. F.; Gyourko, J. 2011. Anatomy of the beginning of the housing boom: U.S. neighborhoods and metropolitan areas, 1993-2009, NBER Working Paper 17374.

Ferson, W. E.; Sarkissian, S.; Simin, T. 2008. Asset pricing models with conditional betas and alphas: the ef- 
fects of data snooping and spurious regression, Journal of Financial and Quantitative Analysis 43(2): 331-354. https://doi.org/10.1017/S0022109000003549

Gray, D. 2012. Region house price movements in England and Wales 1997-2007: an exploratory spatial data analysis approach, Urban Studies 49(7): 14111434 https://doi.org/10.1177/0042098011417020.

Gupta, R.; Miller, S. M. 2012. The time-series properties of housing prices: a case study of the Southern California market, Journal of Real Estate Finance and Economics 44: 339-361. https://doi.org/10.1007/ s11146-010-9234-7

Holmes, M. J.; Grimes, A. 2008. Is there long-run convergence among regional housing prices in the U.K., Urban Studies 45(8): 1531-1544. https://doi. org/10.1177/0042098008091489

Johnes, G.; Hyclak, T. 1999. Housing prices and regional labor markets, Annual of Regional Science 33: 33-49. https://doi.org/10.1007/s001680050091

Kallberg, J. G.; Liu, C. H.; Pasquariello, P. 2014. On the price co-movement of U.S. residential real estate markets, Real Estate Economics 42(1): 71-108. https://doi.org/10.1111/1540-6229.12022

Lean, H. H.; Smyth, R. 2013. Regional housing prices and the ripple effect in Malaysia, Urban Studies 50(5): 895-922. https://doi.org/10.1177/0042098012459582

Lee, C. C.; Chien, M. S. 2011. Empirical modelling of regional housing prices and the ripple effect, Urban Studies 48(10): 2029-2047. https://doi.org/10.1177/0042098010385257

Leung, C. K. Y.; Teo, W. L. 2011. Should the optimal portfolio be region-specific? A multi-region model with monetary policy and asset price co-movements, Regional Science and Urban Economics 41: 293-304. https://doi.org/10.1016/j.regsciurbeco.2010.12.007

Liao, W. C.; Zhao, D.; Lim, L. P.; Wong, G. K. M. 2014. Foreign liquidity to real estate market: ripple effect and housing price dynamics, Urban Studies 52(1): 138-158. https://doi.org/10.1177/0042098014523687

Mankiw, N. G.; Weil, D. N. 1989. The baby boom, the baby bust, and the housing market, Regional Science and Urban Economics 19: 235-248. https://doi.org/10.1016/0166-0462(89)90005-7

Meen, G. 1999. Regional housing prices and the ripple effect: a new interpretation, Housing Studies 14(6): 733-753. https://doi.org/10.1080/02673039982524

Miao, H.; Ramchander, S.; Simpson, M. W. 2011. Return and volatility in U.S. housing markets, Real Estate Economics 39: 701-741. https://doi.org/10.1111/ j.1540-6229.2010.00303.x

Mikhed, V.; Zemcik, P. 2009. Do housing prices reflect fundamentals? Aggregate and panel data evidence, Journal of Housing Economics 18: 140-149. https://doi.org/10.1016/j.jhe.2009.03.001
Patton, A. J. 2006a. Modelling asymmetric exchange rate dependence, International Economic Review 47(2): 527-556. https://doi.org/10.1111/j.14682354.2006.00387.x

Patton, A. J. 2006b. Estimation of multivariate models for time series of possibly different lengths, Journal of Applied Econometrics 21: 147-173. https://doi.org/10.1002/jae.865

Patton, A. J. 2012. A review of copula models for economic time series, Journal of Multivariate Analysis 110: 4-18. https://doi.org/10.1016/j.jmva.2012.02.021

Phillips, P. C. B.; Perron, P. 1988. Testing for a unit root in time series regression, Biometrika 75: 335-346. https://doi.org/10.1093/biomet/75.2.335

Potepan, M. J. 1996. Explaining intermetropolitan variation in housing prices, rents and land prices, Real Estate Economics 24: 219-245. https://doi.org/10.1111/1540-6229.00688

Saks, R. E. 2008. Job creation and housing construction: constraints on metropolitan area employment growth, Journal of Urban Economics 64: 178-195. https://doi.org/10.1016/j.jue.2007.12.003

Sinai, T. M. 2012. House price moments in boom-bust cycles, NBER Working Paper 18059.

Sinai, T.; Souleles, N. 2013. Can owning a home hedge the risk of moving?, American Economic Journal: Economic Policy 5(2), 282-312. https://doi.org/10.1257/pol.5.2.282

Sklar, A. 1959. Fonctions de repartition a n dimentional et leurs marges, Publications de L'Institut de Statistique de L'Universite de Paris 8: 229-231.

Swan, C. 1995. Demography and the demand for housing: a reinterpretation of the Mankiw-Weil demand variable, Regional Science and Urban Economics 25: 41-58. https://doi.org/10.1016/0166-0462(94)02074-Q

Vogiatzoglou, M. 2010. Dynamic copula toolbox [online]. Available at: http://www.downloadplex.com/Publishers/Manthos-Vogiatzoglou/Page-1-0-0-0-0.html

Yunus, N.; Swanson, P. E. 2013. A closer look at the U.S. housing market: modeling relationships among regions, Real Estate Economics 41(3): 542-568. https://doi.org/10.1111/reec.12012

Zhu, B.; Füss, R.; Rottke, N. B. 2013. Spatial linkages in returns and volatilities among U.S. regional housing markets, Real Estate Economics 41(1): 29-64. https://doi.org/10.1111/j.1540-6229.2012.00337.x

Zimmer, D. M. 2012. The role of copulas in the housing crisis, Review of Economics and Statistics 94(2): 607-620. https://doi.org/10.1162/REST_a_00172

Zimmer, D. M. 2015. Time-varying correlation in housing prices, Journal of Real Estate Finance and Economics 51: 86-100. https://doi.org/10.1007/s11146014-9475-y 